\title{
Processing and properties of zirconia-toughened alumina ceramics
}

\author{
D S PATIL* and B C MUTSUDDY \\ Institute of Materials Processing, Michigan Technological University, Houghton, Michigan \\ 49931, USA \\ * Present address: Laser and Plasma Technology Divisjon, Bhabha Atomic Research Centre, \\ Bombay 400085 , India
}

MS received 9 June 1994; revised 30 August 1994

\begin{abstract}
Al}_{2} \mathrm{O}_{3}: \mathrm{ZrO}_{2}$ ceramics have been prepared from physically mixed pure oxide powders. The results indicate that careful processing of the starting powders and a two-stage sintering process can avoid expensive processing methods like hot pressing/hot isostatic pressing used for achieving high densification. The mechanical properties were measured and the resultant microstructure studied to explain the toughening behaviour of this material.
\end{abstract}

Keywords. $\mathrm{Al}_{2} \mathrm{O}_{3} ; \mathrm{ZrO}_{2}$; toughening; gas over pressure sintering.

\section{Introduction}

Alumina has been used more frequently than any other type of ceramic in structural applications. A lot of attention has also been given to improving the mechanical properties of this engineering ceramic. For improvement in the mechanical properties, toughness is one of the most important parameters. One way to improve the fracture toughness is the use of the phenomenon of transformation toughening, which is associated with $\mathrm{ZrO}_{2}$-containing ceramics.

The concept of toughening alumina ceramics by dispersing zirconia particles in the matrix has been recognized in the last decade. The ceramic containing $\mathrm{ZrO}_{2}$ can have relatively high value of fracture toughness. This has been attributed to a number of different mechanisms such as stress-induced tetragonal-monoclinic martensitic transformation (Lange 1982; Ruhle et al 1986), microcracking due to the stress set up in the matrix around $\mathrm{ZrO}_{2}$ particles which have undergone martensitic transformation (Claussen et al 1982; Ruhle et al 1986) and crack deflection around the dispersed $\mathrm{ZrO}_{2}$ particles.

In the zirconia-toughened alumina, retention of $>10 \mathrm{vol} \%$ metastable tetragonal $\mathrm{ZrO}_{2}$ in the alumina matrix is the key to obtaining the increased room-temperature fracture toughness. However, to retain the metastable tetragonal $\mathrm{ZrO}_{2}$ it is essential that $\mathrm{ZrO}_{2}$ grain size be less than some critical size which is reported to be in the range of 0.5 to $0.8 \mu \mathrm{m}$ (Lange and Green 1981; Green 1982; Heuer 1982; Lange 1982; Garvie 1984). Above this critical size, the $\mathrm{ZrO}_{2}$ grains transform to the monoclinic form.

The high temperatures which are required for the densifications usually result in significant grain coarsening and growth of $\mathrm{ZrO}_{2}$ particles above the critical size and therefore it is difficult to retain the desired zirconia volume concentration and phase form. Zirconia grain growth occurs at the elevated sintering temperatures of $>1600^{\circ} \mathrm{C}$. To meet these requirements, numerous processing approaches have been investigated to achieve lower densification temp rature and homogeneous distribution of $\mathrm{ZrO}_{2}$ in the alumina matrix. The methods which are commonly used include attrition milling, colloidal processing, chemical vapour co-deposited alumina zirconia powders 
with a surfactant, co-pyrolysed solutions, hydrothermal reaction of aluminiumzirconium alloys, hydrolysis of zirconium alkoxide in the presence of $\mathrm{Al}_{2} \mathrm{O}_{3}$ particles, polymer/powder flocculation and sol-ge! processing. Leriche et al (1988) obtained $99.3 \%$ density after attrition milling for $6 \mathrm{~h}$ of a mix of two separate slips (of dispersed alumina and zirconia powders) showing same rheological behaviour and sintering in air at $1550^{\circ} \mathrm{C}$ for $2 \mathrm{~h}$. They could get $100 \%$ density for the same samples after hot pressing at $1500^{\circ} \mathrm{C}$ for $15 \mathrm{~min}$ at $30 \mathrm{MPa}$. Mechanical property measurements were done on their samples by Orange et al (1988). For material containing $15 \mathrm{vol}^{\circ} \% \mathrm{ZrO}_{2}$ they obtained a fracture toughness $\left(\mathrm{K}_{\mathrm{IC}}\right)$ value of $6 \mathrm{MPa} \mathrm{m}^{1 / 2}$. For the hot-pressed sample of the same composition $\mathrm{K}_{\mathrm{IC}}$ value was around 6-7 MPa m${ }^{1 / 2}$. Aksay et al (1983) started with colloidal suspension which was further milled for $16 \mathrm{~h}$. Using filtration as a consolidation method and sintering at $1600^{\circ} \mathrm{C}$ in air for $2 \mathrm{~h}$ they obtained density $>98.5 \%$. White et al (1988) started with $0.25 \mu \mathrm{m}$ narrow-sized powders; suspension processing and sintering at $1500^{\circ} \mathrm{C}$ for $2 \mathrm{~h}$ led to a densification around $91-93 \%$.

To avoid grain growth which occurs during pressureless sintering expensive processing like hot pressing/hot isostatic pressing (HIP) is required. However, it is highly desirable to produce structural ceramics with good mechanical properties by conventional processing technique, i.e. normal shaping and simple firing process without expensive processing techniques like hot pressing/hot isostatic pressing. This is particularly advantageous when complicated shapes are required to be made.

The objective of this study was to combine the effects of processing to achieve the high level of densification and fine zirconia phase retention to form toughened alumina-zirconia composites without using expensive high-temperature processing such as hot isostatic or hot pressing.

\section{Experimental}

The starting powder of $\mathrm{Al}_{2} \mathrm{O}_{3}: \mathrm{ZrO}_{2}$ was made by mixing Alcoa Al6SG alumina with average particle size of $0.52 \mu \mathrm{m}$ (Alcoa, Alumina Company of America, Pittsburgh) and Cerac $\mathrm{ZrO}_{2}$ (monoclinic, - 325 mesh) L-1041 (Cerac, Inc., Milwaukee) to get $15 \mathrm{vol}_{\%}^{\circ} \mathrm{ZrO}_{2}$ in the mix. The mixture was rolled with $\mathrm{ZrO}_{2}$ grinding media and isopropyl alcohol for $80 \mathrm{~h}$. The slurry was dried under an IR lamp and the powder was sieved through the 100 mesh screen. The particle size of the $\mathrm{ZrO}_{2}$ in the powder was examined under a JEOL JSM-820 scanning electron microscope (JEOL USA, Inc., Peabody, MA). The zirconia particle size distribution is shown in figure 1. From this figure it is clear that majority of the $\mathrm{ZrO}_{2}$ particles are in the size range around $0.2 \mu \mathrm{m}$.

The powder was cold isostatically pressed into cylindrical pellets at a pressure of $276 \mathrm{MPa}$. The samples were sintered in normal air atmosphere at $1450^{\circ} \mathrm{C}$ for $90 \mathrm{~min}$ (heating and cooling rates of $200^{\circ} \mathrm{C} / \mathrm{h}$ ). The densities of the samples were measured by Archimedes method. The density was $4.150 \mathrm{~g} \mathrm{~cm}^{-3}$, which is $\sim 98 \%$ of the theoretical density (TD, $4.235 \mathrm{gcm}^{-3}$ ).

To enhance further densification, the samples were heat-treated in a graphite furnace. The samples were embedded in boron nitride powder and wrapped in molybdenum foils. The samples were then heated to $1450^{\circ} \mathrm{C}$ and $10.35 \mathrm{MPa}$ argọn gas over pressure was maintained for $2 \mathrm{~h}$. 


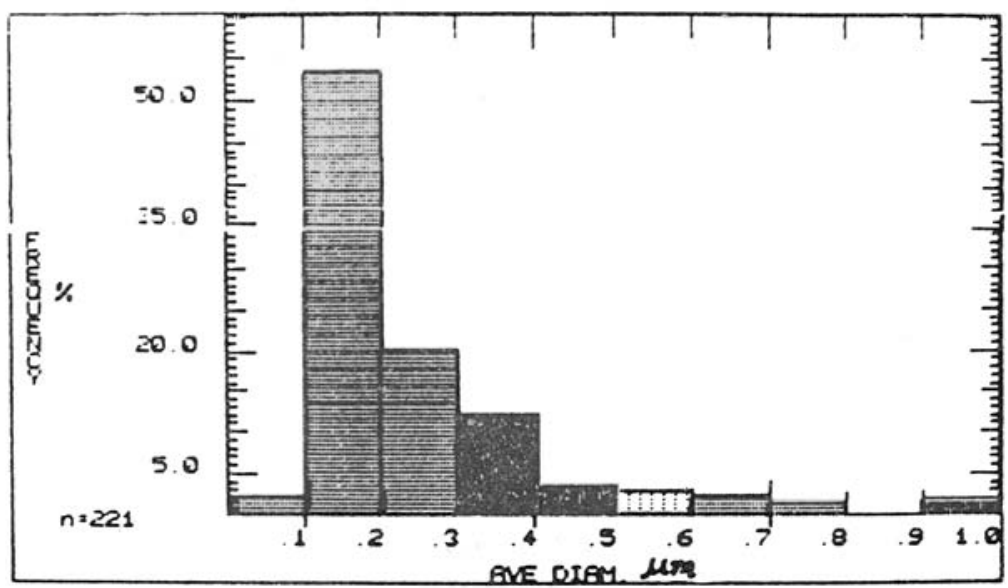

Figure 1. Zirconia particle sizing on the milled $\mathrm{Al}_{2} \mathrm{O}_{3}: \mathrm{ZrO}_{2}$ powder.

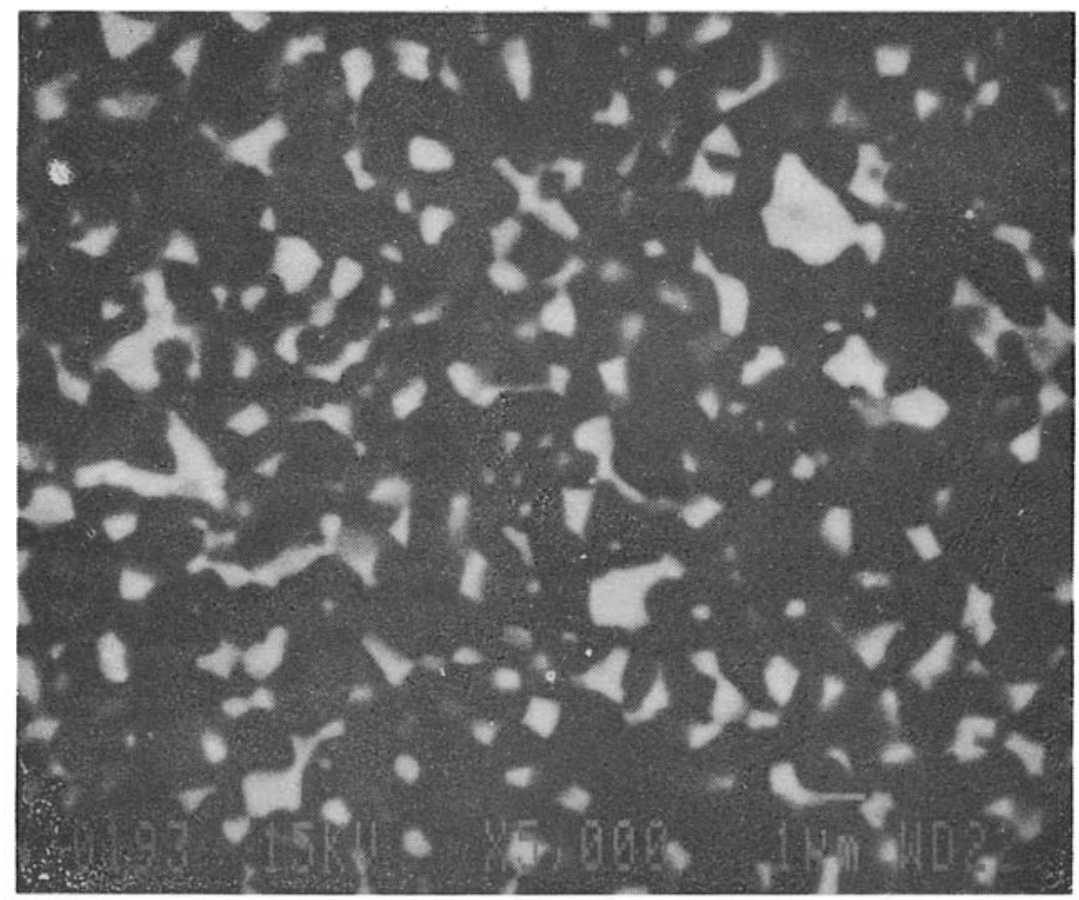

Figure 2. Polished section of sintered $\mathrm{Al}_{2} \mathrm{O}_{3}: \mathrm{ZrO}_{2}(\mathrm{BEI})$.

The densities of the sintered samples were measured after the gas over pressure sintering. Specimens were cut from the sintered samples and the surfaces were polished to a $0.25 \mu \mathrm{m}$ finish with diamond paste. The samples were chemically etched in $40 \%$ hydrofluoric acid (HF) for $2 \mathrm{~min}$ to reveal the microstructure. The polished and etched surface as examined under the scanning electron microscope is shown in figure 2. Zirconia particle sizing was done on the polished section and is shown in figure 3. 


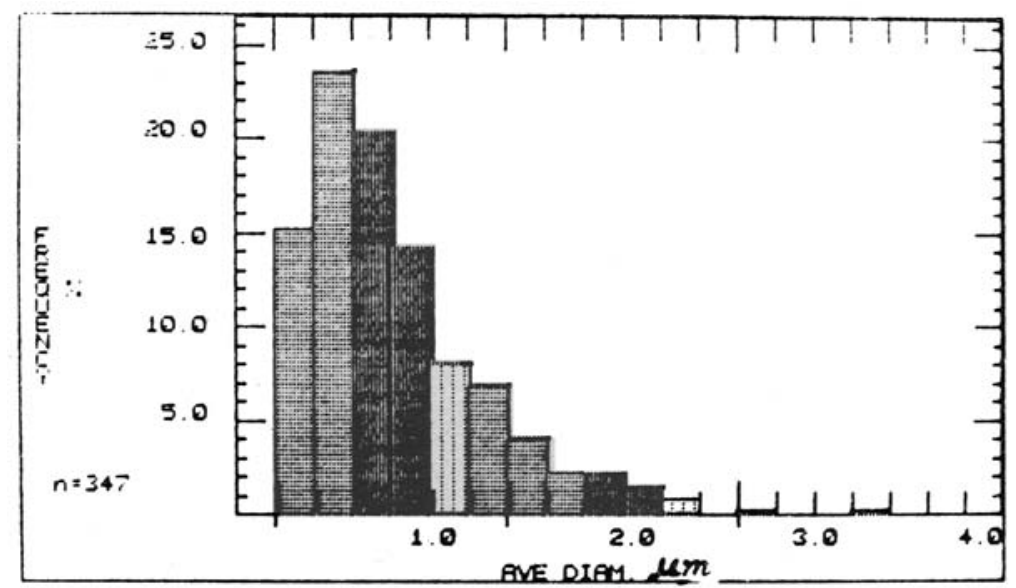

Figure 3. Zirconia particle size distribution on sintered and polished $\mathrm{Al}_{2} \mathrm{O}_{3}: \mathrm{ZrO}_{2}$ surface.

The hardness, fracture toughness and elastic modulus of the polished samples were determined by indentation techniques (Anstis et al 1981; Marshall et al 1982). To produce well-developed microcracks $(c>2 a)$, loads of $10-50 \mathrm{~kg}$ were applied depending upon the samples. Controlled flaws were introduced by Vickers diamond pyramid indenter with loads varying between 10 and $50 \mathrm{~kg}$. The specimens were indented at a constant crosshead speed to the selected load and then slowly unloaded. Hardness values were obtained from these measurements. To calculate the toughness of the material it is essential to know its elastic modulus which has been calculated from the Knoop indentation on the sample. This technique of measuring hardness to modulus ratio is based on measurement of the elastic recovery in surface dimensions of Knoop indention.

\section{Results and discussion}

The density measurements on the samples after the gas over pressure sintering show that the density was $4.233 \mathrm{~g} / \mathrm{cm}^{-3}$. This indicates that the samples were sintered to near theoretical density $(99.95 \%$ of TD). This also confirms that the samples were sintered to closed porosity state by normal air sintering and the gas over pressure sintering was helpful in eliminating the pores further to get full densification. Thus by careful processing of the starting powder (i.e. by making sure that $\mathrm{ZrO}_{2}$ particles are fine and majority of them are within narrow size range) and a combination of air sintering and gas over pressure sintering, it should be possible to densify even complicated shapes of this material without the necessity of expensive processing methods.

The room-temperature hardness and fracture toughness values for this material (values reported here are the average of several measurements) are as follows: Hardness (GPa) 17.8, E/H 23.6, and fracture toughness (MPa m ${ }^{1 / 2}$ ) 4.8.

The data can be explained in the light of the observed microstructure. Fine zirconia particles are retained after sintering as seen in figure 2 . This is further clear from the zirconia particle size distribution on the sintered sample as shown in figure 3 . These 
fine zirconia particles are possibly in the tetragonal form. Presence of these fine zirconia particles gives rise to transformation toughening effects in the wake of the advancing crack and this must be the main contributing factor for the observed hardness and fracture toughness of this material.

\section{Conclusions}

It has been demonstrated that high-density zirconia-toughened alumina ceramics with good mechanical properties can be obtained by careful processing of the initial powder and a combination of air sintering and gas over pressure sintering. These results also indicate that material can be densified to high density without the necessity of expensive hot pressing/hot isostatic pressing.

\section{Acknowledgements}

The authors wish to thank Dr Walter A Johnson, Director, Institute of Materials Processing, MTU, for his continuous encouragement and support. Thanks are due to Ruth Kramer for her assistance with the SEM work and Mr Dennis Moore for his help during the mechanical properties measurements. DSP is grateful to the authorities at the Bhabha Atomic Research Centre, Bombay, for granting him a leave of absence during the course of this work.

\section{References}

Askay I A, Lange F F and Davis B J $1983 \mathrm{~J}$. Am. Ceram. Soc. $66 \mathrm{C} 190$

Anstis G R, Chantikul P, Lawn B R and Marshali D B 1981 J. Am. Ceram. Soc. 64533

Claussen N, Cox R L and Wallance J S $1982 J$. Am. Ceram. Soc. 65 C190

Garvie R C 1984 J. Mater. Sci. Lett. 3315

Green D J 1982 J. Am. Ceram. Soc. 65610

Heuer A H 1982 J. Am. Ceram. Soc. 65642

Lange F F and Green D J 1981 in Advances in ceramics (eds) A H Heuer and L W Hobbs (Columbus, OH: The American Ceramic Society) vol. 3 p. 217

Lange F F $1982 J$. Mater. Sci. 17 225, 235

Leriche A, Moortgat G, Cambier F, Homerin P, Thevenot F, Orange G and Fantozzi G 1988 in Advances in ceramics, Science and technology of zirconia III (eds) S Somiya, N Yamamoto and H Yanagida (Westerville, $\mathrm{OH}$ : The American Ceramic Society Inc.) vol. B24 p. 1033

Marshall D B, Noma T and Evans A G 1982 J. Am. Ceram. Soc. 65 C175

Orange G, Fantozzi F, Homerin P, Thevenot F, Leriche A and Cambier F 1988 in Advances in ceramics, Science and technology of zirconia III (eds) S Somiya, N Yamamoto and H Yanagida (Westerville, $\mathrm{OH}$ : The American Ceramic Society Inc.) vol. B24 p. 1075

Ruhle M, Heuer A H and Claussen N 1986 J. Am. Ceram. Soc. 69195

White P, Bowen H K and Bruce F Jr. 1988 in Advances in ceramics, Science and technology of zirconia III (eds) S Somiya, N Yamamoto and $\mathrm{H}$ Yanagida (Westerville, $\mathrm{OH}$ : The American Ceramic Society Inc.) vol. A24 p. 301 